\title{
Electric Pulp Testing in Children During Permanent Teeth Apexes Formation
}

\author{
PetrikasA*and Letunovskaya SA \\ Department of Therapeutic Stomatology, Tver State Medical University, Russia
}

*Corresponding author: Petrikas A, Department of Therapeutic Stomatology, Tver State Medical University, Russia

\section{Mini Review}

Pain sensation is evolutionarily the primary basis of sensitive human activity, and it is quite stable. The stability of electrodontometry (EOM) indicators is demonstrated by a narrow zone of the pain threshold of 2-6 mkA of healthy front teeth, which was first evaluated by Rubin L. R. in 1953. This value was confirmed by many domestic researchers $[1,2]$. Rubin tried to extend it to all teeth, but the indicators of the lateral teeth, although stable, are 5-15 mkA higher [3-5]. The most important feature of the sensitivity of the dental pulp is that it is represented by an exceptional pain [6,7]. Its sensitivity is very high -2-6 mkA- and sharply differs from the sensitivity of the skin and all surrounding tissues, including the gums and periapical tissues. It is located at the level of 100-200 mkA. The pulp, perceiving tactile, thermal and electrical irritation, translates it into a painful sensation. In the human tooth, the circulatory and nervous systems of the pulp are separated as a thin soft string and are protected from external influences by a thick tube of enamel and dentin. The nerves in the pulp are $20.5 \%$ by weight.The pulp is represented by two main pain points that determine pain sensitivity. In the crown pulp, these are odontoblasts and dentine tubes with 1-2 mm of nerve branches of A-Delta fibers entering them. At the root it is a narrow thin apical part of the canal, where the pulpar nerves of the pulp core from Cfibers are tightly placed together with the blood vessels. Secondary cement is also involved in creating the apical opening, preventing myelination of the nerve tissue there[8]. The presence of myelin A-Delta fibers in the apex has not been proven. Pain fibers A-Delta are slightly myelinated, located in the crown, have a higher rate of conduction (dentin pain). They respond to the pulse current as an acute pain sensation. C-fibers transmit late, dull and not always clear pulp pain. It is interesting that all foreign authors use A-Delta fibers [6], to consider themechanisms of electrodontometry (EOM) from the standpoint of the theory of Branstrom, with an emphasis on EPT (Electrical pulpal test) as dentin stimulation. Foreign researchers exclude the reaction of pain by $\mathrm{C}$-fibers, which make up the bulk of the nerve structures of the tooth.

Interestingly, EPT is rated as a low-value test for primary or permanent teeth during apex formation [9].Many children with normal teeth do not respond even to high stimulation currents [9]. We believe that for the reaction of all neuroreceptors in single teeth, a more universal AC stimulator with a broad total effect, mainly on C-fibers, is needed.The aim of our investigation was: to evaluate tooth maturation in children aged 6.5 - 15 years in dynamics in the study of pain caused by electrotesting in three directions:

a) Reduction of the pain threshold of the central incisors,

b) x-ray width of the apex, and

c) The nature of the pain: pain or not pain.

\section{Material and Methods}

280 teeth were examined in 280 children from 6 to 15 years (central incisors). Patients were divided by age into 5 groups:1 - 6,5 - 7 years; 2 - 7-8years; 3-9-10 years; 4 11-12 years; 5-13-15 years. After receiving informed consent, the oral cavity was examined, the child was instructed, and the central incisors were isolated from saliva. The threshold of pain sensitivity of the dental pulp was determined using the IVN-01 Pulpotest-Pro electrodontodiagnostic device. Measurements were made on the central upper incisor. The pulp tester used created a series of alternating current pulses, devoid of polarization, with a frequency of $50 \mathrm{~Hz}$ with a gradually increasing current strength on a scale from 0 to $200 \mathrm{mkA}$ until the first sensation: pain/non-pain[10-15]. The active electrode was located in a PVC tube into which the contact gel was inserted. The diameter of the active electrode was $4 \mathrm{~mm}$. The passive metal electrode was in the hand of the subject. When pain occurred, the 
subject released the button, thus stopping the current supply, and the value of the EOM was recorded on the display. Indications of the pain threshold after a two-time (one- time) measurement were recorded.In addition to the digital indicator of EOM, the response to electrical stimulation was determined. The main criterion for pain was to divide it into pain / non-pain. All patients according to indications, as a rule, aesthetic, carried out radiography. Intraoral and $\mathrm{x}$-ray images were used to measure the diameter of the tooth apex in $\mathrm{mm}[16-18]$.

\section{Results}

The results are shown in Table 1. Figure 1 shows a descending curve similar for all three parameters under study: EOM, apex, and pain.The highest EOM index was observed in the first age group (140.86 mkA), exceeding that in the second age group by more than 1.5 times ( $91.95 \mathrm{mkA})$. At the same time, the average diameter of the apex decreased from 2.55 to $1.96 \mathrm{~mm}$. For both parameters, the differences between the first and second age groups were statistically significant (t-criteria 5.70 and 6.8, respectively). Between the second and third age groups, the difference in EOM indicators was sharper- $91.95 \mathrm{mkA}$ to $39.75 \mathrm{mkA}$-with almost the

Table 1: Electrodontometry of teeth, apex diameter and sensations (pain, non-pain) in 280 children of different ages.

\begin{tabular}{|c|c|c|c|c|c|}
\hline Indicators & 6,5-7 years & 7-8 years & 9-10 years & $11-12$ years & $13-15$ years \\
\hline \multicolumn{6}{|c|}{ EOM (mkA) } \\
\hline $\mathrm{n}$ & 50 & 62 & 56 & 60 & 52 \\
\hline M & $140,86 \pm 6,12$ & $91,95 \pm 6,01$ & $39,75 \pm 3,55$ & $35,83 \pm 4,30$ & $24,35 \pm 2,92$ \\
\hline SD & 43,31 & 47,29 & 26,55 & 33,31 & 21,02 \\
\hline \multicolumn{6}{|c|}{ Apex (mm) } \\
\hline M & $2,55 \pm 0,07$ & $1,96 \pm 0,05$ & $1,39 \pm 0,04$ & $0,82 \pm 0,03$ & $0,72 \pm 0,03$ \\
\hline SD & 0,53 & 0,36 & 0,31 & 0,26 & 0,24 \\
\hline \multicolumn{6}{|c|}{ Non-Pain } \\
\hline$\%$ & $38 \%$ & $14,5 \%$ & $7,14 \%$ & $5 \%$ & $1,92 \%$ \\
\hline
\end{tabular}

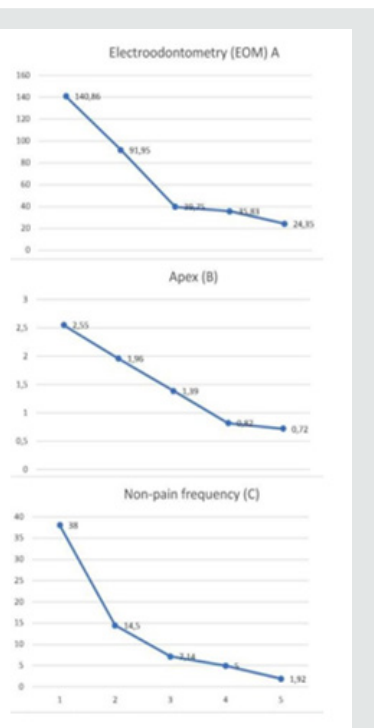

Figure 1: The Value of the pain threshold (A) and the value of the apical opening (B) of the central incisors in children of different ages:1 - 6,5 - 7 years; 2-7-8 years; 3- 9-10 years; 4 11-12years; 5-13-15 years. 


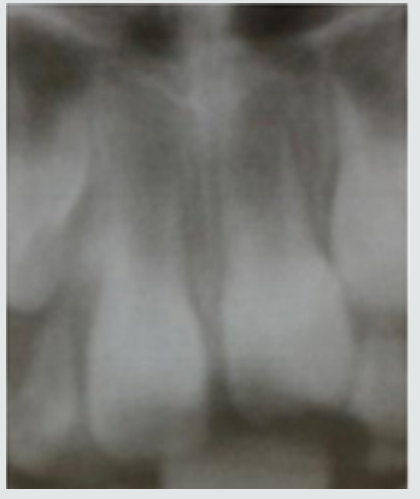

Figure 2: Central incisors of a 6.5-year-old girl. EOM 199 and $195 \mathrm{mkA}$ (apex $3 \mathrm{~mm}$; there is no pain when measuring).

\section{Discussion of Results}

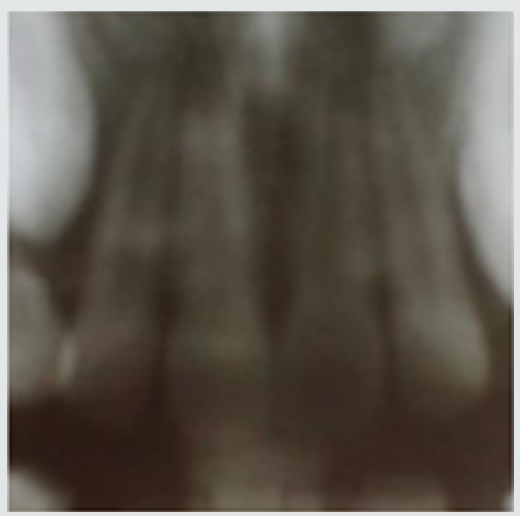

Figure 3: Central incisors of a 12-year-old girl, EOM 13 and $15 \mathrm{mkA}$ (apex $0.8 \mathrm{~mm}$; pain felt during measurement).

Pain is one of the main feelings. With age, the senses improve. The difference in pain assessment is visible on the graph (Figure 1). The youngest ones have the greatest feeling of "non- pain". Children replaced real pain with feelings of cold, heat, etc. We have combined these feelings into the concept of pre-pain.Pain sensitivity of a permanent tooth is the main pain criterion of a person, in which, unlike animals, there is contact with the researcher. The phenomenon of a sharp decrease in the sensitivity of permanent teeth that are in the process of eruption has been established. A close relationship has been established between the reaction of A-Delta fibers and pulsed diagnostic current. The role of C-fibers - the basis of the tooth's nervous system-is underestimated. The electric current due to its strength and the large electrode covers the entire pulp, both coronal and apical (Figure 3). In our literature, there is a tendency to prohibit devices that operate from alternating sinusoidal current with a frequency of $50 \mathrm{~Hz}[1,2]$. The regularities between the degree of tooth eruption and the reduction of its pain threshold to a minimum level, while reducing the apical narrowing, and clarifying the pain response in a young subject were determined. The formation of the apex consists in its gradual narrowing, including ingrowth of cement into the apical part of the root canal. It is dominated by C-fibers. Pulse pulp testers do not "feel" the pulp in the erupting teeth.It should be noted that when the final apex was formed, the threshold value did not always correspond to the previously accepted norm of 2-6 mkA. In one 15 -year-old patient, the initial pain threshold was $125 \mathrm{mkA}$.

\section{Conclusion}

The phenomenon of reducing the pain sensitivity of permanent teeth during eruption due to the reaction of C-fibers has been established. Pulse pulp testers do not work in teeth during apex formation.

\section{References}

1. Makeeva IM et al. (2018) Efficiency of electro-dental diagnostics using various types of current. Dentistry 6: 34-37.

2. Nikolaev AI, E V Petrova (2014) Electrodonto diagnostics Textbook. Med press- inform 6: 34-37.

3. Rubin LR (1976) Elektroodontodiagnostika M p. 136.

4. Mukhin ON (1969) Age-related features of electrical excitability of intact permanent teeth. In the book: Clinic and treatment of congenital and acquired defects of the maxillofacial region p. 179-181.

5. Lubomirski GB (2010) Clinical and electrometric indicators of dentin caries. Cand Diss Perm.

6. Bjorn H (1953) Electric stimulation threshold of teeth with regard to sensitivity in operations involving dentin and pulp. Sven TandlakTidskr 46: 314 .

7. Cohen (2007) Pathways of the Pulp $9^{\text {th }}$ ed, Copyright (C) 2006 Mosby, An Imprint of Elsevier p. 1-18.

8. Harty F (1976) J Endodontic in clinical practice. Bristol p. 235.

9. Camp JH, Barrett EJ, Pulver J (2002) Pediatric endodontic: endodontic treatment for the primary and young permanent dentition. Cohen S RC (Eds.), Burn Pathway of the pulp $8^{\text {th }}$ Edn. 2002: 804-807.

10. Brännström M (1986) The hydrodynamic theory of dentinal pain: Sensation in preparations, caries, and the dentinal crack syndrome. Journal of Endodontics 12(10): 453-457.

11. Chen E, Abbott PV (2009) Dental Pulp Testing: A Review. International Journal of Dentistry (1687-8728): 365785.

12. Trombritge H, Kim S (2002) Structure and function Pulp Complex. Sohep S, Burn RC (Eds.), Pahtways the pulp Mosby p. 430-431.

13. Närhi M, Jyväsjärvi E, Virtanen A, Huopaniemi T, Ngassapa D, etal. (1992) Role intradental A- and C-type nerve fibresindent a lpainmechanisms. Proc Finn Dent Soc 88(Suppl 1): 507-516.

14. Reader A, Nusstein J, Drum M (2017) Successful Local Anesthesia for Restorative Dentistry and Endodontics Quintessence Publishing Co Inc.

15. Moroz VT, Ignatov YUD, Kalinin VI (1989) Threshold of electric excitability of the pulp of various groups of teeth and their changes under the influence of analgin, amidopirin and diazepam. Stomatology 68(4): 30-32.

16.Zyuzkov DI (2004) The condition of the tooth pulp in inflammatory periodontal diseases. Cand Diss Tver.

17. Van TH, JT McSpadden, HE Goodis (2007) Instruments, Materials, and Devices. Cohen (Eds.), Pathways of the Pulp. $9^{\text {th }}$ Ed p. 1-20.

18. Mumford JM, Björn H (1962) Problems in electrical pulp-testing and dental algesimetry. Int Dent J 12: 161. 
This work is licensed under Creative Commons Attribution 4.0 License

To Submit Your Article Click Here: Submit Article

DOI: $10.32474 /$ IPDOAJ.2020.04.000194

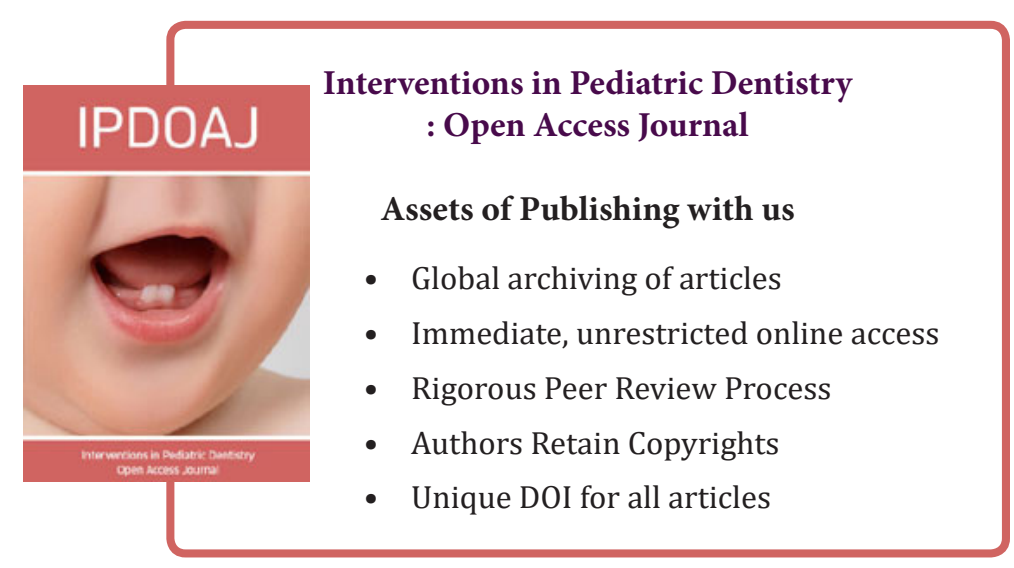

